\title{
Hopes, Fears, and Other Grammatical Scarecrows
}

\author{
Jacob M. Nebel \\ University of Southern California, New York University
}

\section{Two Puzzles about Propositions}

This article is about some puzzles involving propositional attitude reports. The standard view of a sentence like

(1) Sally believes that Fido barks.

is that the verb believes expresses a relation between Sally and the proposition that Fido barks. These relata are the referents of the subject Sally and the complement clause that Fido barks. The same is true, mutatis mutandis, for other verbs with that-clause complements. ${ }^{1}$

Consider, however, the following pair:

(2) a. Sally fears that Fido barks.

b. Sally fears the proposition that Fido barks.

The standard view says that, in (2a), the clause that Fido barks refers to the proposition that Fido barks. On this view, (2a) is true just in case Sally stands in the fears-relation to that proposition. But consider (2b). Surely

Many thanks to Kyle Blumberg, Kara Dreher, Cian Dorr, Harvey Lederman, Peter van Elswyk, and Crispin Wright for helpful comments and discussion. I am especially grateful to Ben Holguín and Jim Pryor for invaluable comments on several drafts, and (most of all) to Stephen Schiffer for guidance and encouragement in early stages of this work.

1. A typographical note: I use italics to quote and mention object-language expressions - except for full sentences, which I surround in quotation marks or indent as numbered examples - and when emphasizing or introducing a term. To avoid confusion, I do not italicize when using foreign phrases. 
the proposition that Fido barks refers to the proposition that Fido barks. ${ }^{2}$ So (2b) should be true just in case Sally stands in the fears-relation to that proposition. But this truth condition is the very same one that the standard view assigns to (2a). And yet, clearly, (2a) and (2b) have different truth conditions: Sally might fear dogs but not propositions; she might fear propositions but not dogs.

This apparent problem for the standard view was first noticed by Prior $(1963,1971)$, so I call it Prior's puzzle. The problem is that the standard view appears to violate

Substitutivity Salva Veritate (Roughly): Coreferential expressions can be substituted for one another while preserving truth value (in extensional contexts).

If the clause that Fido barks refers to the proposition that Fido barks, then we should (in suitable contexts) be able to replace this clause with any coreferential expression salva veritate. In (2a), that Fido barks seems to occur in an extensional context. ${ }^{3}$ And surely the proposition that Fido barks refers to the proposition that Fido barks. So the standard view of propositional attitude reports seems to violate substitutivity salva veritate.

Consider next

(3) a. Sally hopes that Fido barks.

b. *Sally hopes the proposition that Fido barks.

Sentence (3b) is not even well-formed-hence the asterisk. Thus, the standard view appears to violate

Substitutivity Salva Congruitate (Roughly): Coreferential expressions can be substituted for one another while preserving grammaticality (in all contexts). (see, e.g., Wright 1998)

If that Fido barks refers to the proposition that Fido barks, then we should (in any context) be able to replace this clause with any coreferential expression salva congruitate. And surely the proposition that Fido barks refers to the

2. I here ignore the possibility that definite descriptions are not referring expressions-partly because (following King 2002) I suspect that the data would not be much less puzzling if reframed in terms of some semantic function other than reference.

3. This assumption might be questioned. I simply take it for granted here, since it seems to be common ground among those who discuss this puzzle. It is defended more explicitly by Betti $(2015,133)$ on the grounds that substitutions like (2) are relevantly unlike substitutions within clausal complements. Proponents of the standard view who reject this assumption would owe us some account of why believes that $p$ and believes the proposition that $p$ always mean the same thing. 
proposition that Fido barks. So (3) seems to show that the standard view of propositional attitude reports violates substitutivity salva congruitate. This problem for the standard view was first pressed by Rundle (1967), so I call it Rundle's puzzle.

Some philosophers believe that these substitution failures undermine-or, at least, provide strong evidence against — the standard view of propositional attitude reports. Such philosophers conclude that propositional attitude reports do not report relations between agents and propositions (Bach 1997; Moltmann 2003), that that-clauses often refer to entities other than propositions (Parsons 1993; Moffett 2003; Harman 2003), or that that-clauses enjoy some nonreferential semantic relation to what may or may not be propositions (Rosefeldt 2006; Pryor 2007).

I disagree. ${ }^{4}$ I argue that the substitution failures are consistent with the standard view of propositional attitude reports. The substitution failures are mere "grammatical scarecrows" (Geach 1972, 169): at best, they reflect interesting quirks of natural languages, but they should not scare us off an otherwise attractive philosophical view.

My strategy is, first, to reduce Rundle's puzzle to Prior's puzzle. I argue that the proper substitution instance for a sentence like (3a) is not (3b), but rather

(4) Sally hopes for the proposition that Fido barks.

I claim that the definite description in (4) complements the very same verb that occurs in (3a) - the two-word lexeme hopes for-but that the preposition for is suppressed in (3a) in accordance with the rules of English grammar. However, although this substitution preserves grammaticality, it results in a different meaning. So the requirement of substitutivity salva congruitate is met in a way that seems to violate substitutivity salva veritate. My solution to Rundle's puzzle, therefore, requires a solution to Prior's puzzle. I conjecture that, in sentences like (4) and (2b), the proposition that Fido barks does not in fact denote a proposition. It, therefore, does not denote the same thing as the clause that Fido barks. It will take some work to explain what it does denote. But the resulting account allows us to solve Prior's puzzle, Rundle's puzzle, and some other puzzles to be introduced. ${ }^{5}$

4. So do King (2002), Schiffer (2003), Boër (2009), and Künne (2014).

5. Since I end up denying that the proposition that $p$ denotes a proposition, my response to Rundle's puzzle may seem unnecessary. But my response to Rundle's puzzle helps motivate some key moves in solving Prior's puzzle in sections 3 and 4.3. It is also of 


\section{Rundle's Puzzle}

I motivate my solution to Rundle's puzzle in section 2.1 by considering a related puzzle involving adjective complementation, to which the solution seems to me more obvious. In section 2.2, I explain why and how the requirement of substitutivity salva congruitate must be weakened to allow for my solution to the puzzle about adjective complementation. In section 2.3, I show how that solution can be naturally extended to solve Rundle's puzzle.

\subsection{Adjective Complementation}

My solution to Rundle's puzzle begins with a different structure-adjective complementation - which has not been much discussed in the philosophical literature on that-clauses. ${ }^{6}$ Consider the following sentences:

(5) a. Sally is afraid that Fido barks.

b. *Sally is afraid the proposition that Fido barks.

The complement clause in (5a) is not replaceable salva congruitate by the proposition that Fido barks. ${ }^{7}$ Nor is it replaceable by any other proposition description - that is, any description of the form the F that $p$. Why not?

The reason is not, I think, that the clausal complements of adjectives do not refer to propositions. There is a simpler answer. The simpler answer appeals to the fact that proposition descriptions can complement adjectives only when marked by a preposition — but not just any preposition will do:

(6) a. Sally is afraid of the proposition that Fido barks.

b. *Sally is afraid in/under/after/on the proposition that Fido barks.

Our limited flexibility in choice of prepositions suggests that the definite description in (6a) denotes a prepositional argument of the relation

independent interest for those who reject my solution to Prior's puzzle. And even if the proposition that $p$ does not denote a proposition, it is worth leaving open the possibility that some noun phrase complement of some verb like hopes denotes a proposition; even this weak possibility requires something like my solution to Rundle's puzzle.

6 . Künne $(2003,2014)$ mentions but does not discuss adjectives. He simply assumes that they are relevantly like hopes. Betti (2015) uses a substitution failure involving happy to argue that that-clauses are not singular terms.

7. Although I use afraid in all examples in this section, I also intend my claims to apply to related adjectives, such as happy, sorry, confident, honest, and hopeful. 
expressed by afraid of. ${ }^{8}$ It is an argument, as opposed to the object of an adjunct phrase. And it is a prepositional argument, as opposed to a direct argument (e.g., the argument of a transitive verb). The following examples, based on Merlo and Ferrer 2006, illustrate the contrasts:

(7) a. Sally studies philosophy.

b. Sally is a student of philosophy.

c. Sally is a student from Florida.

In (7a), philosophy denotes an argument of the relation expressed by studies. In (7b), philosophy denotes an argument of the relation expressed by student of. The preposition in $(7 \mathrm{~b})$ makes this argument prepositional rather than direct. But philosophy is an argument in both cases, unlike Florida in (7c), which is the object of an adjunct phrase. Intuitively, (7c) does not mean that Sally bears the student-from relation to Florida; it means that Sally is a student, and that she is from Florida. By contrast, (7b) does not mean that Sally is a student, and that she is "of philosophy"; it means that she studies philosophy. ${ }^{9}$ The interpretation of of philosophy depends on its associated head student, whereas from Florida has a relatively constant meaning (see Grimshaw 1992). Similarly, "Sally is afraid of dogs" does not mean that Sally is afraid and also "of dogs." The interpretation of of dogs depends on the adjective afraid.

The distinction between arguments and adjuncts is somewhat slippery; we need not put much weight on it here. The point is that afraid of functions as a single lexical unit in (6a). (6a) is true just in case Sally stands in the afraid-of relation to the referent of the proposition that Fido barks. This reading of (6a) helps explain why (5b) - "Sally is afraid the proposition that Fido barks" - is ill-formed, because it explains why the preposition after afraid is necessary when the complement is a noun phrase. But so what? (5a) — "Sally is afraid that Fido barks" — does not say that Sally stands in the afraid-of relation to anything. It only contains afraid, followed by a that-clause. Why think that my reading of (6a) tells us anything about (5a)?

I claim that (5a) represents Sally as standing in the afraid-of relation to the referent of that Fido barks, just as (6a) represents Sally as stand-

8. Similar claims apply to happy (about), sorry (for/about), confident (in/about), honest (about), and hopeful (of/about). Deutscher (2000) uses oblique where I say prepositional. See also Loukanova and Jiménez-López 2012.

9. Some might suggest that nominal complements of adjectives are adjuncts because they are optional: "Sally is afraid" is fine. But although all adjuncts are optional, not all arguments are obligatory. 
ing in this same relation to the referent of the proposition that Fido barks. But the preposition is suppressed in (5a) due to a rule of English grammar: namely, that prepositions cannot preface the complementizers that, for, or to (Dixon 2005, 232). That is why (8) is ill-formed:

(8) *Sally is afraid of that Fido barks.

How do we know that this rule explains the absence of a preposition in (5a)? Why not think instead that (8) is unacceptable simply because that Fido barks cannot denote an argument of the afraid-of relation, contrary to my reading of (5a)? I offer three reasons to favor my account.

First, we can rescue the preposition by stating Sally's attitude in a nonrestrictive relative clause:

(9) That Fido barks, which Sally was afraid of, was clear.

The relative clause in (9) seems to express a side remark that is true just in case Sally was afraid that Fido barks (see Heim and Kratzer 1998, 64). And, in (9), which seems to refer anaphorically to the referent of the subject clause that Fido barks. This would seem hard to explain on the hypothesis that that Fido barks cannot denote an argument of the afraid-of relation. But it is exactly what we would expect if, as I have claimed, the clausal complement in (5a) denotes the prepositional argument of the afraid-of relation, but the preposition is omitted because it cannot precede the complementizer that.

Second, prepositions can precede wh-complementizers. For example,

(10) Sally was afraid of whether Fido barks.

The wh-clause complement of (10) denotes an argument of the afraid-of relation in (10). This would seem hard to explain on the hypothesis that that-clauses cannot denote arguments of this relation, because the whclause in (10) and the that-clause in (5a) seem to play the same semantic roles: they denote things that Sally is (reportedly) afraid of.

Third, the absence of a preposition between adjectives and their that-clause complements is merely a quirk of certain natural languages. In some other languages, a preposition may (in some cases, must) precede a clausal complement wherever it would precede a noun phrase (Božković $1995,49)$. For example, in Norwegian,

(11) a. Sally er $[\operatorname{redd}$ for $] /[$ skuffet over $] /[$ sikker $p a ̊] /[\operatorname{glad}$ for $]$ at Fido bjeffer. 
Sally is [afraid $\left.\vartheta^{f}\right] /[$ disappointed $] /\left[\right.$ certain $\left.\theta^{f}\right] /[$ happy about ] that Fido barks.

b. Sally er $[$ redd for $] /[$ skuffet over $] /[\operatorname{sikker} p a ̊] /[\operatorname{glad}$ for $]$ Fido. Sally is [afraid of $] /[$ disappointed about] $/$ [certain of $] /$ [happy about] Fido.

Since the grammatical rule I have cited is just a quirk of some natural languages, my hypothesis would lead us to expect that declarative clausal complements could denote overtly prepositional arguments in languages without that rule. And that is just what we see in (11). ${ }^{10}$

We have seen three environments in which our hidden preposition reappears: nonrestrictive relative clauses, interrogative clauses, and other languages. These considerations suggest that, in (5a) — "Sally is afraid that Fido barks" - the preposition is absent only because English forbids prepositions from preceding the complementizer that. This makes it plausible that (5a) is true just in case Sally stands in the afraidof relation to the referent of that Fido barks, just as (6a) - "Sally is afraid of the proposition that Fido barks" - is true just in case Sally stands in the afraid-of relation to the referent of the proposition that Fido barks.

But how exactly does this help us solve Rundle's puzzle? We still get gibberish if we replace an adjective's that-clause complement with a proposition description and leave the other words in the sentence as they are. Maybe I am right about why we get gibberish. But the requirement of substitutivity salva congruitate, as I introduced it in section 1, does not care about that. It lists no exceptions for the removal or addition of prepositions. To utilize my appeal to prepositional arguments in a solution to Rundle's puzzle, we must weaken or reinterpret the requirement of substitutivity salva congruitate. That is the task of section 2.2.

\subsection{Revising Substitutivity Salva Congruitate}

The principle of substitutivity salva congruitate is false, as I stated it in section 1. That is why I qualified it with "roughly." 11 There is no reason to suppose that coreferential expressions should be grammatically intersubstitutable in any context, in any natural language, with no manipulation of the expressions' surrounding environment. Consider, for example, the

10. Thanks to Knut Skarsaune for helpful discussion of these examples.

11. I qualified substitutivity salva veritate in the same way because preservation of truth value requires preservation of grammaticality. 
following substitution of a name for a first-person pronoun (see Oliver 2005):

(12) a. I am writing.

b. *Jake am writing.

Does (12) show that Jake cannot refer to the same person as the occurrence of $I$ above? Of course not. ${ }^{12}$ The proper substitution of Jake for $I$ is not (12b), but rather, "Jake is writing." The ill-formed substitution in (12b) does not undermine the coreferentiality of I and Jake. It shows only that we have to conjugate verbs.

That is just one example in which simple substitution of coreferential expressions fails to preserve grammaticality. Other examples involve apposition (Schiffer 2003), premodifying adjectives (Oliver 2005), and noun gender (Dolby 2009).

What do we learn from these apparent counterexamples to the requirement of substitutivity salva congruitate? It would be hasty to conclude that there is nothing to the requirement and that Rundle's puzzle is in no way puzzling. It is more reasonable to conclude that the principle should be revised, restricted, or reinterpreted in some way to accommodate the complexities of natural language. I do not know exactly how the principle should be revised. But I submit that any plausible version of the principle must allow for my response to the substitution failures involving adjective complements.

Consider, for example, a revision suggested by Dolby (2009). Dolby suggests that we revise the relevant notion of substitution. In (12), I simply replaced one expression with another without changing anything else in the sentence. Call that copy-paste substitution. Copy-paste substitution is not a proper test of coreference, because it yields false negatives, as in (12): some coreferential terms cannot always be copy-paste substituted for one another while preserving grammaticality. Dolby suggests instead that a proper substitution instance should follow a two-step procedure. First, we extentially generalize the sentence with respect to the initial expression, making whatever changes are required by the grammatical rules of the language. (12a), for example, would be existentially generalized as, "Someone is writing." Then we specify the generalization with respect to the substitute expression, also making whatever changes grammar requires. Thus, "Someone is writing" would be specified as "Jake is

12. Fancy views about first-person pronouns are irrelevant here, because the same problem occurs for the intersubstitutability of $I$ and me, and for he and him. 
writing," which provides the intuitively correct test of whether I and Jake corefer. Call this process Dolby substitution.

Dolby substitution cannot take us from a well-formed sentence to an ill-formed one-we make whatever changes are needed to preserve grammaticality along the way - so it may seem unable to provide a useful test of coreference. But, Dolby suggests, it is not trivial whether any given expression is, in some or any context, Dolby-intersubstitutable salva congruitate with another. For there may be no grammatical rules to guide us through one of the steps of existential generalization or specification. For example, Dolby insists that there are no such rules for the substitution of is a horse for the concept horse. If that is right, then Dolby substitution may provide a nontrivial test of coreference while avoiding the standard counterexamples to substitutivity salva congruitate.

Can we Dolby-substitute proposition descriptions for the that-clause complements of adjectives? We can, if we help ourselves to my proposal in section 2.1. We can existentially generalize (5a) — "Sally is afraid that Fido barks" - with respect to that Fido barks, as follows:

(13) Sally is afraid of something.

The arguments of section 2.1 make it plausible that (13) is a legitimate way of existentially generalizing ( $5 \mathrm{a}$ ). And this generalization can be specified as (6a): "Sally is afraid of the proposition that Fido barks." That is how we Dolby-substitute proposition descriptions for the that-clause complements of adjectives.

I have some reservations about the notion of Dolby substitution. ${ }^{13}$ I doubt it handles all possible counterexamples to the simple requirement of substitutivity salva congruitate. ${ }^{14}$ Unfortunately, I do not know of a better alternative in the literature. I am not confident that there is an informative, extensionally adequate universal generalization to be found

13. Trueman (2012) claims that Dolby's proposal is viciously circular because it presupposes that we know which substitutions are grammatical. Some kind of circularity along these lines seems to me inevitable, as Trueman (2018) later seems to admit.

14. Some verbs can only be followed by reflexive pronouns (Dixon 2005, 64). Consider "The mayor prided herself on the performance." The following substitution instance (where Sally is the mayor) is ungrammatical: "The mayor prided Sally on the performance." But herself and Sally should refer to the same person. It is hard to see how Dolby substitution can secure that result: "The mayor prided someone on the performance" is ungrammatical. (The problem is not just that reflexive pronouns function as bound variables, because we can Dolby-substitute Sally for herself in "The mayor hit herself.") 
in the vicinity of substitutivity salva congruitate - nor do I feel particularly responsible for discovering it if there is one. But any plausible version of the requirement should, like Dolby's, allow us to mark a prepositional argument with a preposition when substituting a noun phrase (which requires the preposition) for a that-clause (which forbids the preposition) - just as it would have to allow for other rule-governed manipulations of context (e.g., conjugating verbs). I cannot prove this. But I think it is suggested by the following vague, but plausible, generic generalization: coreferential expressions can typically be copy-paste substituted for one another while preserving grammaticality; when they cannot be, it is because of some identifiable quirk of the language, and we should expect some simple, principled manipulation of context to provide a wellformed substitution. I have shown that to be true of the substitution failures involving adjective complements. In the next section, I extend my account to verbs like hopes in an effort to solve Rundle's puzzle.

\subsection{Resolving Rundle's Puzzle}

I have argued that the proper substitution instance for a sentence like (5a) - "Sally is afraid that Fido barks" — is not (5b) — "Sally is afraid the proposition that Fido barks" - but rather (6a) - "Sally is afraid of the proposition that Fido barks." I suggested that this manipulation is legitimate because the preposition is omitted in (5a) only due to a quirk of English, which prohibits prepositions from preceding the complementizer that.

How can this account help us solve Rundle's puzzle? Recall (3):
a. Sally hopes that Fido barks.
b. *Sally hopes the proposition that Fido barks.

Why is (3b) ungrammatical? The answer is that noun phrases can complement hopes (and its ilk, including wishes, cares, complains, brags, insists, rejoices, and agrees) only when following a preposition - but not just any preposition will do: ${ }^{15}$

15. The corresponding forms for the other verbs in this category are wishes (for), cares (about), complains (about), brags (about), insists (on), rejoices (in), and agrees (on). Some other verbs that might seem to be like hopes in resisting complementation by proposition descriptions should be treated separately: dreams, thinks, reminds, decides, persuades, warns, informs, boasts, and says. These verbs still require prepositions when followed by most noun phrases, with seemingly principled exceptions (Dixon 2005). Dreams and thinks can be followed by quantifiers (e.g., something) and cognate noun phrases-for example, dreamed 
(14) a. Sally hopes for the proposition that Fido barks.

b. *Sally hopes in/on/through the proposition that Fido barks.

Our limited choice of prepositions with which to follow hopes suggests that, in (14a), the referent of the proposition that Fido barks is a prepositional argument of the relation expressed by the two-word lexeme hopes for, as opposed to the object of an adjunct phrase (see Dixon 2005). This distinguishes hopes from, say, arrives: you can arrive at noon, after work, before dark, by train, or in a car. This difference can be observed by considering transformations to the passive voice:

(15) a. *The holiday was arrived before by Sally. ${ }^{16}$

b. The holiday was hoped for by Sally.

Sentence (15a) seems unacceptable, or at least less acceptable than (15b), because "Sally arrived before the holiday" does not mean that Sally stood in some arrived-before relation to the holiday. The prepositional phrase before the holiday is an adjunct. (15b), by contrast, seems acceptable because "Sally hoped for the holiday" means that Sally stood in the hopedfor relation to the holiday.

I claim that (3a) — "Sally hopes that Fido barks" - is true just in case Sally stands in the hopes-for relation to the referent of that Fido barks. But the preposition is omitted because English does not allow prepositions to precede the complementizer that.

Why think this reading of (3a) is correct? Why not think instead that that-clauses simply cannot denote the arguments of hopes for, and that they therefore cannot refer to the same things as proposition descriptions? The main reason is that my interpretation is a natural extension of

\footnotetext{
a dream and thinking happy thoughts - but other noun phrases must be introduced by a preposition (e.g., of, about, or up). Reminds, persuades, warns, and informs can be followed by noun phrases that refer to an agent; there remains an argument place for what the agent is reminded, persuaded, warned, or informed of or about. Boasts seems ambiguous: you can boast something (i.e., by having it as a feature) without boasting of or about it. The most interesting case is says. You can say quite a lot of things: words, phrases, sentences, statements, prayers, things, stuff, numbers, names, thoughts, and lines. And although says can be followed by a small number of prepositions (e.g., of or about), there remains an argument place for a that-clause. So it differs greatly from the other verbs discussed in this section. For that reason, I am inclined to think that "Sally said the proposition that Fido barks" is grammatical but false. But I agree that says is a difficult case and that much more can be said about this verb.

16. See Takami 1992 for discussion of many similar examples.
} 
what we observed about adjective complementation in section 2.1. But I offer two more reasons.

First, the preposition is mandatory if we transform (3a) to the passive voice:

(16) That Fido barks is hoped for by Sally.

Clearly, however, (16) and (3a) share the same truth condition. This makes it highly plausible that, in (3a), that Fido barks denotes the argument of the hopes-for relation, even though no preposition is voiced in (3a).

Second, I mentioned in section 2.1 (see (10)) that prepositions can precede wh-complementizers. Unfortunately, hopes for does not take interrogative clause complements. But we can consider another verb that is otherwise relevantly like hopes:

(17) a. Sally cares that Fido barks.

b. *Sally cares the proposition that Fido barks.

c. Sally cares about the proposition that Fido barks.

d. Sally cares about whether/why Fido barks.

Cares is relevantly like hopes, as $(17 \mathrm{a})-(17 \mathrm{c})$ show. In $(17 \mathrm{c})$, the proposition that Fido barks denotes the prepositional argument of cares about. And the corresponding preposition reappears in $(17 \mathrm{~d})$, when its complement is an interrogative clause. This strongly suggests that the preposition is omitted in (17a) only because English does not allow prepositions to precede the complementizer that. And it would be surprising if this were true of cares but not of hopes and other relevantly similar verbs.

I have given two reasons to think that (3a) — "Sally hopes that Fido barks" - represents Sally as standing in the hopes-for relation to the referent of that Fido barks. Even if these reasons are not decisive, the obvious similarity to the structure of adjective complementation makes it hard to resist this reading of (3a). How does this help us solve Rundle's puzzle?

I argued in section 2.2 that substitutivity salva congruitate must be understood in a way that allows for certain manipulations of the surrounding context. For example, the proper substitution of Jake for $I$ in "I am writing" is "Jake is writing." If I am right that it is legitimate to add a preposition when substituting proposition descriptions for the clausal complements of adjectives, then it is hard to deny that (14a) - "Sally hopes for the proposition that Fido barks" - should be the proper sub- 
stitution instance of (3a). ${ }^{17}$ To see this, let us apply Dolby's substitution test sketched in section 2.2. We existentially generalize (3a) as

(18) Sally hopes for something.

That (18) is the correct way to existentially generalize (3a) is made plausible by the data I have presented in this section. ${ }^{18}$ And we get (14a) by specifying this generalization with respect to the proposition that Fido barks.

Even if we have reservations about Dolby substitution in particular, it is clear that my suggested manipulation should be kosher on any plausible requirement of substitutivity salva congruitate. For we can explain the ungrammaticality of $(3 b)$ - "Sally hopes the proposition that Fido barks" - in a simple, principled way without denying that that-clauses refer to propositions.

Of course, there is still a puzzle, because (3a) and (14a) have different truth conditions. But that is an apparent violation of substitutivity salva veritate, not of substitutivity salva congruitate. It is no longer puzzling that replacing a that-clause complement of hopes with a noun phrase fails to preserve grammaticality. We would not expect that substitution to preserve grammaticality, even on the assumption that that-clauses refer to propositions, because the substitution of a noun phrase for the clausal complement of hopes requires us to reintroduce a preposition (in something like the way in which the substitution of coreferential nouns and pronouns requires us to conjugate verbs). Thus, we have reduced Rundle's puzzle to Prior's puzzle in the following sense: if we can solve Prior's puzzle - if we can explain why sentences like (3a) and (14a) have different truth conditions in a way that is consistent with the standard view of propositional attitude reports - then there is no further apparent violation of substitutivity salva congruitate to be explained. This result will help us make progress on Prior's puzzle, as we will see in section 3.

17. Of course, when I call (14a) the proper substitution instance of (3a), I do not mean that they have the same truth conditions. I just mean that the ungrammaticality of (3b) does not demonstrate a violation of substitutivity salva congruitate, properly understood, and that if (14a) were ungrammatical, then there would be a violation substitutivity salva congruitate.

18. King (2002, 364) and Moltmann (2013, 127) find sentences like "Sally hopes something" acceptable. I do not. 


\section{The Proliferation of Polysemy}

To solve Prior's puzzle in a way that is consistent with the standard view of propositional attitude reports we need to explain why sentences like (2a) — "Sally fears that Fido barks" — and (2b) — "Sally fears the proposition that Fido barks" - have different truth conditions even though that-clauses refer to propositions.

King (2002) offers a simple explanation: fears is ambiguous (or polysemous). Its meaning depends on the syntactic category of its complement: it expresses one relation in (2a) and another in (2b). More generally, on King's view, each verb that gives rise to Prior's puzzle expresses one relation when complemented by a that-clause and another relation when complemented by a noun phrase. ${ }^{19}$ This claim would, if true, solve Prior's puzzle in a way that allows that-clauses and proposition descriptions to refer to the same things.

We are now in a position to see, however, that a full solution to Prior's puzzle must also apply to a wider range of substitution failures, such as (19) and (20):

(19) a. Sally is afraid/happy/sorry/confident/honest/hopeful that Fido barks.

b. Sally is [afraid of $] /[$ happy about $] /[$ sorry about/for $] /[$ confident in/about]/[honest about]/[hopeful of/about] the proposition that Fido barks.

(20) a. Sally hopes/wishes/cares/complains/brags/insists/rejoices/ agrees that Fido barks.

b. Sally [hopes for $] /[$ wishes for $] /[$ cares about $] /[$ complains about $] /[$ brags about $] /$ [insists on] $/[$ rejoices in] / [agrees on] the proposition that Fido barks.

To solve Prior's puzzle, King's proposal would have to extend to adjectives and verbs with prepositional arguments. If it cannot plausibly extend to those other expressions, then we should reject it in favor of a more complete solution (if there is one). For it would be incredible if the (a)- and (b)-sentences in (2), (19), and (20) had different truth conditions for entirely different reasons. The problem seems to be the same in all three cases.

19. King claims that believes and other verbs that do not give rise to Prior's puzzle are not ambiguous along this dimension. Also, King (2007, chap. 4) remains open to the possibility that some that-clauses designate nonpropositional entities such as facts. 
But adjectives like afraid and verbs like hopes are not plausibly ambiguous in the way that King's solution (if extended) would require. I will start with verbs. Consider the following sentences uttered (or typed) in the wild:

(21) Others hoped for a quick and painless death, and that they would be able to remain in their own home to that point. (Healthtalk Australia 2016)

(22) The MMs only care about themselves and that they can buy shares at a lower price, to sell to retail investors like us later at higher prices. (FastMny [pseud.] 2017)

(23) I complained about the broken AC and that they did not even have breakfast.... (Balou18 [pseud.] 2010)

(24) The mothers of two children (patients five and six) insisted on operations and that they be simultaneous. (Klemens, Mhoon, and Redleaf 2007, 1042)

I have bolded the complements of each verb to highlight the fact that a single occurrence of each verb takes both noun phrase and that-clause complements. If verbs with prepositional arguments were ambiguous in the way required by an extension of King's proposal, then we would expect (21) - (24) to sound bad-more specifically, zeugmatic. By way of contrast, consider

(25) a. Sally called my bluff.

b. Sally called her grandmother.

c. ?Sally called my bluff and her grandmother.

Called is ambiguous. It has one sense in (25a) and another in (25b). That is why (25c) is infelicitous, except perhaps as a joke: the single use of called cannot express both the relation in which Sally might stand to my bluff and the relation in which she might stand to her grandmother. The strangeness of (25c) is what I am calling zeugma. But (21)-(24) are not zeugmatic. They are not jokes. Nor are they products of contrived philosopher-speak. They are sincere, easily interpretable utterances by ordinary speakers of what may be literal truths. This strongly suggests that verbs like hope, care, complain, and insist are not ambiguous in the way that King's solution (if extended) would require.

We observe a similar effect with adjectives:

(26) The Soviet authorities are genuinely afraid of a religious revival and that the "contagion" of religion will spread. (J. Ellis 1980, 100) 
(27) To be certain of consistency within analysis and that similar views were held regarding the interpretation of data and the formation of themes, each researcher initially focused on the analysis of one theme. (Gott et al. 2004, 530)

(28) They are sorry for the wasted years and that police records have closed many doors to possible careers. (Bahna and Gordon 1978, 654)

The acceptability of these examples as nonjoke utterances makes it implausible that adjectives like afraid, certain, and sorry are ambiguous in the requisite way.

It would not be promising to respond to this evidence by refusing to extend King's proposal beyond verbs like fears. For even if we could develop some other solution to the substitution failures in (19) and (20), there is similar evidence against the ambiguity of fears:

(29) They fear the pregnancy and that it will destroy their well-arranged lives. (Interviewee quoted in Mishtal 2009, 173)

(30) I love the quietness of L.A. and that you can just keep your head down and work. (Jennifer Meyer quoted in Felder 2017)

(31) But I still liked the idea of David and that he existed. (B. E. Ellis 2015)

(32) The initial recruitment letter for the experiment explained the purpose and that it was being conducted by Copenhagen Business School. (Harrison, Lau, and Yoo 2014, 9)

These examples count against King's proposed ambiguity even if we do not try to extend it to verbs like hopes or adjectives like afraid. And I do not see how the proposal could be revised to predict ambiguity in Prior's puzzle but not in the examples above.

These examples may not be decisive-for example, because certain kinds of polysemy have been claimed not to elicit zeugma in certain contexts. ${ }^{20}$ I do not know of a foolproof test of monosemy. But the data above should, at the very least, adjust the burden of proof. Absent strong evidence to the contrary, we should presume that our verbs and adjectives of propositional attitude are not ambiguous between senses that take clausal complements and senses that take noun phrase complements (even if they are in other ways ambiguous, polysemous, or context-sensitive). If we can solve Prior's puzzle in some other way, then we should

20. See, e.g., Asher 2011. Felappi (2015) argues that the zeugma test is not sufficiently reliable to show whether or not propositional attitude verbs are ambiguous. 
reject King's proposed ambiguity because it multiplies senses beyond necessity. $^{21}$

The arguments of this section illustrate how my solution to Rundle's puzzle is of importance to Prior's puzzle. By reducing Rundle's puzzle to Prior's puzzle, we have decreased the number of puzzle-types to be solved. This makes our task in one way easier. But Prior's puzzle is now seen to be tokened by many other expressions: all those that gave rise to Rundle's puzzle, which we saw to include many adjectives in addition to verbs. This makes our task in another way harder, because we now need a solution to Prior's puzzle that extends to these new expressions. King's solution seems not to fit the bill. I present an alternative solution to Prior's puzzle in the next two sections.

\section{Concealed Questions}

My solution to Prior's puzzle is best motivated by considering another putative substitution failure. Consider the following sentences:

(33) a. The teacher explained the cause of World War I.

b. The teacher explained the assassination of Franz Ferdinand.

c. The cause of World War I was the assassination of Franz Ferdinand.

(34) a. The number of insect species on Earth is astonishing.

b. 5.5 million is astonishing.

c. The number of insect species on Earth is 5.5 million.

21. It might be argued that King has provided strong evidence to the contrary. For example, King observes that gapping constructions like, "Sally fears that it will rain, and John the proposition that it will snow," sound bad, which seems hard to explain on the hypothesis that fears is univocal. I do not have a simple explanation of this data. But the data seems to me more complicated than King suggests. Some gapping constructions along these lines seem relatively acceptable — e.g., "Sally fears that it will rain, and John the possibility that it will snow." And analogous sentences involving believes-e.g., "Sally believes that it will rain, and John the proposition that it will snow"- do not strike me as obviously acceptable, even though believes is univocal on King's view. Analogous pseudogapping constructions involving believes - e.g., "Sally believes that it will rain as strongly as John does the proposition that it will snow"-sound even worse. These complications lead me to suspect that the sentences in question sound bad because they violate independent constraints on gapping (and pseudogapping), not because their verbs are polysemous. For example, Jackendoff (1971) suggests that gapping is unacceptable (or at least difficult) when multiple unlike constituents follow the deleted verb, including a noun phrase followed by a that-clause. 
Why do the (a)- and (b)-sentences above have different truth conditions, if the (c)-sentences are true? Plausibly, it is because the definite descriptions the cause of World War I, the assassination of Franz Ferdinand, and the number of insect species on Earth do not refer to the thing that caused World War I, the event of Ferdinand's assassination, and the number 5.5 million in (33a), (33b), and (34a), respectively. Instead, they serve as concealed questions (Baker 1968; see also Heim 1979, Nathan 2006, Romero 2006, Aloni 2008, Aloni and Roelofsen 2012, Percus 2014, and Barker 2016). (33a), for example, can be naturally paraphrased as, "The teacher explained what caused World War I." (34a) can naturally be paraphrased as, "It is astonishing how many insect species there are on Earth." And these interrogative clauses - what caused World War I and how many insect species there are on Earth-do not refer to assassinations or numbers.

What, then, are the semantic values of the definite descriptions in (33) and (34)? That is a controversial issue, which I say more about in section 5.2. For now, the important point is merely that the arguments of explained and is astonishing in these sentences are not causes, assassinations, or numbers. They are the kinds of things expressed by concealed questions, whatever those are.

I have just given some examples of concealed questions. I will now argue that, in some cases, the proposition that $p$ does not refer to the proposition that $p$, but serves instead as a concealed question. This will help us solve some instances of Prior's puzzle. This partial solution will lead the way to a more general solution in section 5 .

\subsection{Application to Prior's Puzzle}

My proposal in this section only works for certain verbs-namely, those that take wh-clause complements. These include explains, knows, understands, guesses, reveals, finds out, and cares about (among others). I focus on explains, but I take my proposal to apply to the other verbs in this category, too. ${ }^{22}$ Although the proposal does not solve all instances of Prior's puzzle, it suggests a natural generalization, which I explore in section 5.

22. It is controversial whether knows, like the others in this group, gives rise to Prior's puzzle, or whether it is more like believes despite taking interrogative complements. I am inclined to agree with Harman (2003) that knows does give rise to Prior's puzzle: its thatclause complements are not intersubstitutable salva veritate with proposition descriptions. I suspect that intuitions to the contrary are driven by distinctively philosophical patterns of use. 
Consider the following instance of Prior's puzzle:

a. Sally explained that Fido barks.

b. Sally explained the proposition that Fido barks.

These two sentences have different truth conditions. How can this be explained on the standard view of propositional attitude reports? I suggest that, in (35b), the proposition that Fido barks does not denote the proposition that Fido barks - that is, the referent of that Fido barks-but rather serves as a concealed question. ${ }^{23}$ What question does it conceal? I will get to that in a few paragraphs. For now, I just want to argue that it conceals some question or other.

My main reason for reading the proposition that Fido barks as a concealed question in (35b) is that verbs like explains only take noun phrase complements when those complements serve as concealed questions. Thus, (36a) is acceptable; (36b) is not:

(36) a. Sally explained the cause of World War I.

b. *Sally explained the brick.

The cause of World War I conceals a question in (36a), which can be paraphrased as what caused World War I. So we know that explain can embed concealed questions. However, it does not take just any noun phrase complement-witness (36b). (36b) is unacceptable-or, at least, very hard to interpret-because the brick does not naturally serve as a concealed question (for reasons I discuss in section 4.4). (36b) can seem barely acceptable in certain contexts, when there is a salient question under discussion about some brick. If you found a brick on your desk and Sally explained why it was there, you might utter (36b). But when there is no salient question for the brick to conceal, (36b) is unacceptable for that reason.

More generally, verbs like explains take noun phrase complements when and only when those complements conceal questions. ${ }^{24}$ And we know from (35b) that the proposition that Fido barks can complement such verbs. So it must serve as a concealed question. On this reading of (35b), the proposition that Fido barks does not denote the proposition that Fido

23. A similar suggestion is made by Uegaki (2016) in response to other data.

24. At least in the relevant senses of those verbs. I am open to the possibility that some verbs of propositional attitude are ambiguous or polysemous in certain ways - just not that they are systematically ambiguous or polysemous in the sweeping way discussed in section 3 . 
barks - that is, the referent of that Fido barks - so it need not be intersubstitutable salva veritate with that Fido barks, just as the number of insect species on Earth does not denote the number 5.5 million and thus need not be intersubstitutable with 5.5 million in (34). This reading lets us solve the relevant instances of Prior's puzzle while maintaining that that-clauses refer to propositions.

This reading of (35b) naturally invites us to ask, what question does the proposition that Fido barks conceal? The answer is not obvious to me. For some verbs - for example, explains, understands, and knows - the complement seems to conceal a question like what the proposition that Fido barks is/means/involves. But I admit that such a paraphrase is not obvious, and that the complements of other verbs - for example, guesses and reveals - are even less readily paraphrased in that way. However, this nonobviousness strikes me as a virtue, not a vice, of my proposal. Sentences like (35b) are strange. It is not clear what it means to explain, know, understand, guess, or reveal a proposition. This is not just because proposition has both a technical and a nontechnical sense. For we can obtain similar sentences that are similarly hard to interpret involving nontechnical terms like thought and rumor. The difficulty of interpreting these sentences is, I think, explained by the hypothesis that the proposition that Fido barks serves as a concealed question, along with the fact that no particular question is salient in the context. If we supply such a question - for example, by supposing that Sally is a contestant (or host) on a game show and has to guess (or reveal) which proposition is the content of some person's attitude, or what proposition (in the nontechnical sense of proposition) someone has offered-then the sentence may become easier to interpret. So we should not reject the concealed question reading simply on the grounds that it is not always obvious which question is concealed. For we should not expect strange sentences like (35b) to have obvious, straightforward meanings.

I have suggested that in (35b) the proposition that Fido barks serves as a concealed question-even if it is not obvious what question it conceals-on the grounds that verbs like explains take noun phrase complements only when they conceal questions. I highlight two other virtues of this proposal in sections 4.2 and 4.3 .

\subsection{Belief Reports}

Any solution to Prior's puzzle must explain why the puzzle does not arise for believes (and certain other verbs, such as assumes, asserts, grants, and 
denies) — that is, why "Sally believes that Fido barks" and "Sally believes the proposition that Fido barks" have the same truth conditions. Appealing to concealed questions goes some way toward such an account, because believes does not take interrogative clause complements:

(37) *Sally believes whether/what/where/how/why/when Fido barks. ${ }^{25}$

This is important because verbs that do not take interrogative clause complements cannot be complemented by concealed questions (Baker 1968). Thus, (38) is unacceptable (or at least very difficult to interpret):

(38) *Sally believes the cause of World War I.

Since believes does not take concealed question complements, we would not expect the proposition that Fido barks to serve as a concealed question in the sentence, "Sally believes the proposition that Fido barks." And it does not. The absence of a concealed question reading for believes thus helps explain why believes does not give rise to Prior's puzzle. This provides some evidence that at least some instances of Prior's puzzle are explained by concealed question readings of proposition descriptions.

\subsection{Künne's Puzzle}

My appeal to concealed questions also offers a simple solution to a related puzzle, which we have not yet discussed. Künne $(2003,2014)$ points out that, in certain cases, proposition descriptions cannot grammatically be replaced by that-clauses:

(39) a. Sally and Fred debated the proposition that Fido barks.

b. *Sally and Fred debated that Fido barks.

Rundle's puzzle involved verbs that seemed to take that-clause complements but not noun phrase complements. Künne's puzzle, by contrast, involves verbs that take noun phrase complements but not that-clause complements. (This category includes entertains, describes, and analyzes, to which my claims below also apply.)

My solution to Rundle's puzzle does not apply to Künne's puzzle, because there is no preposition in (39a) to mark a prepositional argu-

25. We can say, "Sally believes what you said," but that is a free relative clause, which is distinct from interrogative clauses in several important ways. One simple morphological test is whether the $w h$-word can be suffixed by -ever: if so, then it is a free relative pronoun, not an interrogative complementizer (Bresnan and Grimshaw 1978). 
ment. But my appeal to concealed questions does apply, because debates takes interrogative clause complements:

(40) Sally and Fred debated whether/why Fido barks.

We should therefore expect debates to embed concealed questionswhich it does:

(41) Sally and Fred debated the cause of World War I.

And, like explains, debates resists noun phrase complements that do not readily conceal questions:

(42) *Sally and Fred debated the brick.

Sentence (42) is unacceptable, or at least very hard to interpret (except perhaps in contexts where some particular question about the brick is salient).

These considerations suggest that the proposition that Fido barks serves as a concealed question in (39a). It does not refer to the proposition that Fido barks. ${ }^{26}$ Thus the proposition that Fido barks (when it complements debates and its ilk) need not be intersubstitutable salva congruitate with that Fido barks. This solution to Künne's puzzle is, I think, a significant advantage of my appeal to concealed questions.

\subsection{Sortal Nouns vs. Relational Nouns}

I have suggested that proposition descriptions sometimes conceal questions. I motivated this suggestion, in part, by contrasting the acceptability of proposition descriptions with the unacceptability of the brick as the complements of question-embedding verbs. I now consider an objection to my proposal. The objection is that proposition descriptions are not the kinds of noun phrases that can conceal questions: they are more like the brick than like the cause of World War I.

Why is the brick unable to conceal a question (in normal contexts)? Barker (2016) suggests the following answer, following Löbner (1981) and Nathan (2006): it is because brick is a sortal noun. Sortal nouns are

26. It might seem surprising that, on my view, debates does not express a relation to propositions. But, in an indirect sense, it does. On the view sketched in section 5.2, questions denote functions whose values are propositions. Thus, for example, to debate whether Fido barks is, indirectly, to bear a certain relation to the propositions that Fido barks and that Fido does not bark, via the question to which these propositions are the possible answers. 
supposed to be nouns that express properties of individuals - unlike relational nouns, which express two-place relations between individuals. For example, whereas day is a sortal noun, birthday is a relational noun: any birthday is the birthday of someone - not so for day. Whereas animal is a sortal noun, pet is a relational noun: any pet is someone's - not so for animal. The distinction between sortal and relational nouns is slippery. But, however we carve out that distinction, proposition might appear to be a paradigm case of a sortal noun (see Partee and Borschev 2012). Propositions are not things possessed by or otherwise related to people or other individuals. If proposition is a sortal noun, then proposition descriptions might seem unable to conceal questions, contrary to my proposal here.

It is not clear to me that proposition is a sortal noun. If propositions are (say) functions from possible worlds to truth values, then proposition would seem to count as a relational noun. But even if we grant that proposition is a sortal noun, sortal nouns can head concealed questions when modified in certain ways. Here are some examples due to Barker (2016):

(43) a. *Sally found out the animal.

b. Sally found out Fred's favorite animal.

(44) a. *Sally found out the street.

b. Sally found out the street that the restaurant is located on.

The (a)-sentences above suggest that sortal nouns do not readily lend themselves to interpretation as concealed questions. But the (b)-sentences show that such nouns can serve as concealed questions when modified by favorite or certain relative clauses. (43b) can be paraphrased as, "Sally found out what Fred's favorite animal is." (44b) can be paraphrased as, "Sally found out which street the restaurant is located on."

Why is it important that sortal nouns can conceal questions when modified in these ways? It is important because even if proposition is a sortal noun, the proposition that Fido barks may be modified in a way that makes it suitable to conceal a question. ${ }^{27}$ Some people hold that that Fido barks functions as a relative clause in the proposition that Fido barks (Kayne 2009; Arsenijević 2009; Haegeman 2012). This would make proposition descriptions relevantly analogous to the definite description in (44b). Others hold that that Fido barks is an adjunct that modifies the proposition (Cuba

27. See Löbner $(1985,299)$, who lists "an abstract sortal head noun and a subordinate clause which explicitly specifies a certain abstract entity of the sort indicated" as a kind of "functional concept." 
2017). Even on that kind of view, the proposition that Fido barks would seem to be a suitable concealed question, because other postnominal modifiers seem to allow sortal nouns to conceal questions (Nathan 2006, 118) —as in

(45) Sally found out the person responsible.

The person responsible can be paraphrased as which person was responsible. If, more generally, postnominal modifiers can turn sortal nouns into concealed questions, then proposition descriptions can conceal questions even on the view that that Fido barks (as it occurs in the proposition that Fido barks) is a modifying adjunct rather than a relative clause.

I have suggested that, on at least two different views about the function of that-clauses in proposition descriptions, such descriptions can serve as concealed questions even if their head nouns are sortal. But we have also seen more direct evidence that proposition descriptions can conceal questions: if they could not conceal questions, then (like the brick) they would not so readily complement verbs like explains and debates. Even if the evidence presented so far is not decisive, we will encounter an additional reason to admit proposition descriptions as concealed questions in section $5 .^{28}$

\subsection{Summary}

I have suggested that the proposition that $p$ sometimes conceals a question, rather than referring to the proposition denoted by that $p$. This explains why, in certain contexts, the proposition that $p$ need not be intersubstitutable salva veritate or salva congruitate with that $p$. And it also helps explain why Prior's puzzle does not arise for certain verbs. But the account does not provide a complete solution to Prior's puzzle, because some predicates that give rise to Prior's puzzle do not take interrogative clause complements. This is true of fears and hopes (for). In section 5, I sketch a more

28. Another objection to my appeal to concealed questions is that it cannot explain why substitutions of proper names (e.g., logicism) or indefinite descriptions (e.g., a proposition) for that-clauses do not preserve truth value. But both names and indefinites can conceal questions. Barker (2016) gives an example for names: if Sally is asked to match the names of world leaders with the names of the countries they led, we might say, "Sally only knew Obama," to mean that Sally only knew the country led by Obama (i.e., which country Obama led). Frana (2006) argues that sentences like, "John knows a doctor that can treat your illness," have concealed-question readings (in addition to acquaintance readings). I give a more general treatment of these variants in section 5.1. 
general solution to Prior's puzzle that is motivated by my appeal to concealed questions.

\section{Propositional Concepts}

The original version of Prior's puzzle with which I began this article involved the predicate fears: when Sally fears that Fido barks, she need not fear the proposition that Fido barks. In section 2, we saw that this same puzzle afflicts adjectives like afraid (of) and verbs like hopes (for). We cannot completely solve the puzzle by appealing to concealed questions, because some of these predicates do not take wh-clause complements:

(46) *Sally fears/hopes (for) whether Fido barks.

Many other verbs and adjectives are also limited in this way-for example, loves, hates, despises, sorry (for), happy (about), and surprised (by). ${ }^{29} \mathrm{We}$ therefore need a more general solution to Prior's puzzle than my appeal to concealed questions. I sketch such a solution in 5.1, relate it to concealed questions in 5.2, and return to the anomaly of belief reports in section 5.3. The result is a general solution to Prior's puzzle and a host of related puzzles that is independently confirmed by the concealedquestion data of section 4 .

\subsection{Partee's Puzzle}

The solution begins with a different puzzle, due to Partee 1974. Consider the following argument:

(47) a. The number of insect species on Earth is increasing.

b. The number of insect species on Earth is 5.5 million.

c. Therefore, 5.5 million is increasing.

This argument is invalid. But its invalidity is hard to capture if (47a) predicates a property - the property of increasing — of the number of insect species on Earth, which (47b) identifies with the number 5.5 million. For then the number 5.5 million would have that property too, as $(47 \mathrm{c})$ says. Although we have seen that the number of insect species on Earth

29. Although these predicates can embed some apparent wh-clauses-e.g., "Sally feared what sharks might do"- these are free relative clauses, not interrogative clauses, as evidenced by the fact that the $w h$-word can be suffixed by -ever (see note 25). This reading is also supported by the fact that these verbs do not embed whether-clauses, since predicates that embed interrogative clauses should be able to embed whether-clauses. 
can conceal a question rather than denoting a number, this problem cannot be solved merely by appealing to concealed questions, because increasing does not embed questions.

I take for granted a simple solution to Partee's puzzle that combines two insights.

The first insight, due to Montague (1973), is that the number of insect species on Earth does not denote a number, but rather an individual concept. An individual concept is a function from situations (more formally, indices of evaluation, understood as world-time pairs) to individuals. The number of insect species on Earth denotes a function that takes a situation and returns the number of insect species on Earth at that situation. (47a) says that this function is increasing - that is, that its value is an increasing function of time - not that 5.5 million is increasing. For Montague, this is accomplished compositionally by letting number, along with many other common nouns, denote a set of individual concepts. The number of insect species on Earth denotes one element of that set.

But if the number of insect species on Earth denotes an individual concept in (47a), then won't this phrase have to be ambiguous? Won't it have to denote a number in (47b), on pain of identifying an individual concept with a number?

The second insight is that no such ambiguity is required: the copula in (47b) is not equative but is instead specificational (in the taxonomy of Higgins 1973). It does not identify the denotation of the number of insect species on Earth with the number 5.5 million. Instead, it specifies the value of the individual concept at the relevant situation. Since $(47 \mathrm{~b})$ does not identify the function denoted by the number of insect species on Earth with the number 5.5 million, the function can have properties that the number lacks, thereby allowing $(47 \mathrm{c})$ to be false.

Other solutions to Partee's puzzle, including subtle variants of this solution, are possible. I want to assume that something like the solution I have described is correct, but I suspect that my claims below can be modified to make sense on other solutions to the puzzle. ${ }^{30}$ I adopt the Montagovian solution for concreteness and simplicity, to provide a proof of concept. My aim is to illustrate how we can, in principle, solve Prior's puzzle by assimilating it to Partee's puzzle. What matters is that we have

30. For example, we might hold that the number of insect species on Earth denotes a number (or other individual) but that predicates take individual concepts as their arguments via a rule of intensional functional application (Heim and Kratzer 1998). I mention how this kind of alternative could be extended to solve Prior's puzzle in note 35 . 
some way of explaining the invalidity of (47) and, crucially, that the explanation accounts for the following datum: the noun phrases that give rise to Partee's puzzle also tend to be eligible as concealed questions (Löbner 2015). Recall that the number of insect species on Earth was one of my examples of a concealed question in section 4: "The number of insect species on Earth is astonishing" means that it is astonishing what that number is. This datum - that the noun phrases that give rise to Partee's puzzle make good concealed questions - is important for the following reason. I claimed in section 4 that proposition descriptions conceal questions in certain environments. If that is true, then we should expect them to give rise to versions of Partee's puzzle. And they do:

(48) a. The rumor is that Jim consumes peyote.

b. The rumor is vicious.

c. Therefore, that Jim consumes peyote is vicious.

(49) a. The evidence that vaccines cause autism is that vaccines contain thiomersal.

b. The evidence that vaccines cause autism is scant.

c. Therefore, that vaccines contain thiomersal is scant.

These arguments are invalid. But their invalidity would seem hard to capture if (48a) and (49a) assert identities between some rumor or evidence and the denotation of a that-clause, and if that denotation is the argument of is vicious or is scant. ${ }^{31}$ These examples seem to me relevantly like Partee's puzzle. The resemblance seems especially striking and important

31. An anonymous reviewer suggests that these invalidities might not be hard to capture, on the grounds that nouns like rumorare ambiguous: in one sense, rumordenotes some rumored content; in another, it denotes the state of propagating that content. On this view, (48) is ambiguous because the predicate in (48a) selects for the content-sense, whereas the predicate in (48b) selects for the state-sense. But consider other nouns, such as observation and construction, that we independently know to be ambiguous in this way: in one sense, these expressions denote things that are observed or constructed; in another sense, the state of observing or constructing them-hence the infelicitousness (or, at least, zeugma) of sentences like, "The observation, which lasted an hour, was that Edward was a vassal in Aquitaine," and "The frequent construction is a library." If rumor were similarly ambiguous, we would expect sentences like, "The rumor, which is vicious, is that Jim consumes peyote," and "The vicious rumor is that Jim consumes peyote," to sound similarly bad, due to conflicting selection requirements imposed by the two predicates (cf. Pryor 2007 on desire and purchase). But these sentences are perfectly acceptable. I am therefore unconvinced that nouns like rumor are ambiguous between states and contents. At the very least, if we can explain the invalidity of (48) and (49) without positing such an ambiguity, that would seem preferable, other things being equal. 
given my appeal to concealed questions in section 4: if some instances of Prior's puzzle can indeed by solved by treating proposition descriptions as concealed questions in certain environments, then, since question-concealing expressions give rise to Partee's puzzle, we have reason to expect invalidities like (48) and (49) to be explained by some extension of a solution to Partee's puzzle. And it seems reasonable to expect such an explanation to deliver a solution to Prior's puzzle.

The insight that (48) and (49) are relevantly like Partee's puzzle is important for two reasons: first, because it supports my claim in section 4 that proposition descriptions can serve as concealed questions, since the constructions that give rise to Partee's puzzle tend also to conceal questions; second, because a simple solution to Partee's puzzle can be extended in a natural way to solve Prior's puzzle.

The solution I have in mind appeals to simple analogues of the two insights about (47).

First, expressions like the rumor and the evidence do not denote rumors, evidence, or other proposition-like entities. They denote propositional concepts, on the model of individual concepts. The rumor denotes a function that takes a situation and returns the proposition that is rumored to be true at that situation. The evidence that $p$ denotes a function that takes a situation and returns the relevant proposition that provides evidence for $p$ at that situation. The values of these functions are propositions - for example, that Jim consumes peyote and that vaccines contain thiomersal. The arguments of vicious and scant in (48b) and (49b) are not propositions, but propositional concepts.

Second, the $i$ of (48a) and (49a) is a specificational copula rather than an equative one (Pryor 2007). (48a) and (49a) specify the contents of the rumor and the evidence, rather than identifying the rumor and the evidence with their contents. (49a) is true just in case the value of the rumor at the present situation - that is, the proposition rumored to be true-is that Jim consumes peyote. (49a) is true just in case the relevant value of the evidence that vaccines cause autism at the present situation - that is, the proposition that evidences that vaccines cause autism-is that vaccines contain thiomersal. These assumptions yield the desired result: the rumor and evidence can be vicious and scant without their contents being vicious or scant, so the (c)-sentences do not follow from the (a)- and (b)sentences.

This story would, if correct, allow us to solve Prior's puzzle. Just as it is plausible that loving or fearing the number of insect species on Earth is not loving or fearing a number, so it is plausible that loving or fearing the 
proposition that Fido barks is not loving or fearing a proposition. Such attitudes are rather to be understood as loving or fearing some function whose values are numbers or propositions. And one can love or fear the function without loving or fearing its values. Thus, "Sally fears that Fido barks" and "Sally fears the proposition that Fido barks" have different truth conditions because the argument of fears is a proposition in the former sentence and a propositional concept in the latter.

Which function from situations to propositions does the proposition that Fido barks denote? We can take it to denote the constant function that returns, at each world, the proposition that Fido barks. Fears takes this function and returns a predicate that is true of an individual just in case she fears the proposition that Fido barks. By contrast, when fears is fed the proposition that Fido barks - rather than the constant function with this proposition as its value - it returns a predicate that is true of an individual just in case she fears that Fido barks. One and the same verb (fears) takes different arguments (propositions and propositional concepts), thereby returning different values. Of course, I have not explained why this verb should return such different values for constant propositional concepts. But we have no more reason to expect it to return the same values than we have to expect it to return different values. Fears is far from alone in this behavior. The pattern seems to hold for most verbs that embed both that-clauses and proposition descriptions, including (for variety, not completeness) see, hear, feel, expect, desire, notice, show, recognize, discover, overlook, imagine, remember, forget, sense, teach, conclude, suspect, resolve, sing, read, announce, report, mention, suggest, promise, threaten, cheer, like, hate, and many others. What cries out for explanation is not that these verbs return different values for propositions and propositional concepts, but rather that believes (among a handful of other verbs) does not. I return to this question in section 5.3.

I said that the proposition that Fido barks denotes a constant propositional concept. But I do not want to assume that all propositional concepts are constant functions. For example, the evidence that Fido barks would seem to return a different proposition at different situations, depending on which proposition evidences that Fido barks at that situation. The rumor that Fido barks might denote a propositional concept that returns the proposition that Fido barks at all situations where that proposition is rumored to be true, and no proposition otherwise.

This solution to Prior's puzzle applies to all predicates of propositional attitude, not just ones that embed questions. Proposition descriptions univocally denote propositional concepts, not propositions. 
This view might seem somewhat paradoxical. For it might seem to predict that the following sentence should be false: ${ }^{32}$

(50) The proposition that Fido barks is a proposition.

For if the proposition that Fido barks does not denote a proposition, then how could (50) be true?

The first thing to note is that a parallel problem would seem to arise for any simple Montagovian solution to Partee's puzzle. If the number of insect species on Earth denotes an individual concept, not a number, then we might expect the following sentence to be false:

(51) The number of insect species on Earth is a number.

But remember (from our discussion of (47)) that, for Montague, the number of insect species on Earth gets its individual-concept denotation compositionally: number denotes a set of individual concepts, and the definite description denotes a particular member of that set. (51) is true because the individual concept denoted by the number of insect species on Earth is indeed a member of the set of individual concepts denoted by number.

This suggests an analogous account of (50). On my extension of the Montagovian story, proposition - along with other content nouns like evidence, rumor, and so on-always denotes a set of propositional concepts. The proposition that Fido barks denotes a particular member of that set. That is why (50) is true, even though the proposition that Fido barks does not denote a proposition.

This account suggests a simple solution to a variant of Prior's puzzle involving indefinite descriptions:

(52) a. Kim fears that nuclear war is imminent.

b. Kim fears a proposition.

(52a) does not entail (52b). This might seem hard to explain on the view that that-clauses denote propositions.

My appeal to propositional concepts, however, suggests a simple solution to this variant of Prior's puzzle. In (52b), proposition denotes a set of propositional concepts. The sentence is true just in case Kim fears some member of that set. Kim might fear that nuclear war is imminent without fearing any propositional concept. That is why (52a) does not entail (52b).

32. I am grateful to an anonymous reviewer for raising the issues discussed in the remainder of this subsection. 
What about variants involving names? Consider:

(53) a. Gödel feared that arithmetic reduces to logic.

b. Gödel feared logicism.

Again, (53a) seems not to entail (53b).

This kind of example is not addressed by anything we have seen so far. But I suggest that, on my extension of the Montagovian picture, logicism-along with other -isms - should also denote a propositional concept: it should denote the same constant propositional concept as the proposition that arithmetic reduces to logic. This suggestion seems to me plausible, given the naturalness of speeches like

(54) Logicism is (identical to) the proposition/claim/doctrine that arithmetic reduces to logic,

compared to the relative unnaturalness of speeches like

(55) ?Logicism is (*identical to) that arithmetic reduces to logic.

I do not insist that all -isms denote constant propositional concepts. Perhaps some denote variable propositional concepts, whose values change between worlds or over time. For example, some might take Trotskyism to denote a doctrine whose content at a world and time depends, at least in part, on the views attributed to Leon Trotsky at that world and time.

The suggestion that logicism denotes a propositional concept may seem ad hoc, on the grounds that ordinary proper names denote individuals. But, in fact, there is precedent for claiming that names denote individual concepts - constant ones, if names are rigid designators. Abbott (2010; 2011), for example, argues that such a strategy is helpful in solving the problem of empty names and in drawing the distinction between "specific" and "nonspecific" indefinites. ${ }^{33}$ Although I do not insist that ordinary proper names denote individual concepts, it seems to me reasonable to allow -isms to denote propositional concepts, given the Montagovian picture in the background. At the very least, I lack any strong pretheoretical inclination to think that such expressions must denote propositions rather than nearby entities.

I have suggested that proposition descriptions denote propositional concepts, not propositions. This allows us to solve Prior's puzzle

33. See also Janssen 1984 on Geach's (1980) "herald names," Aloni 2005 on attitude reports, and Elbourne 2009 on demonstratives. Another interesting function of individual concepts, in the theory of arbitrary objects, is suggested by Kripke (1992). 
as well as its variants involving indefinites and names. But this proposal invites the following questions. First, how does this solution to Prior's puzzle fit with my appeal to concealed questions in section 4? And, second, if we accept this solution, then how could we possibly explain why Prior's puzzle does not arise for believes? I answer these questions below.

\subsection{Concealed Questions Revisited}

In section 4, I suggested that proposition descriptions sometimes serve as concealed questions, and that this accounts for some instances of Prior's puzzle. But if the solution to other instances of Prior's puzzle is something entirely different - an appeal to propositional concepts — then we seem to have a highly disunified account of a seemingly unified phenomenon.

However, my hypothesis that proposition descriptions denote propositional concepts and my claim that they sometimes serve as concealed questions are mutually reinforcing. For, as I have already mentioned, the noun phrases that give rise to Partee's puzzle also tend to make good concealed questions. This has led many people to seek an account of concealed questions in terms of individual concepts. Some suggest that concealed questions denote individual concepts (Heim 1979; Romero 2005; Frana 2010). Others suggest that concealed question readings might arise because, in certain environments, individual concepts get type-shifted into question meanings (Barker 2016). We need not choose between these different views here. The point is that on any plausible account of concealed questions we should expect a systematic connection between concealed questions and the noun phrases that denote individual (or propositional) concepts and give rise to Partee's puzzle.

For example, it is natural to think that concealed questions denote whatever interrogative clauses denote. And what do such clauses denote? On one view, they denote question intensions. A question intension is a function that takes a situation and returns the proposition that truly and exhaustively answers the question in that situation (Groenendijk and Stokhof 1982; Aloni and Roelofsen 2012). On this view, what caused World War I denotes a function that, when applied to our actual situation, returns the proposition that the assassination of Ferdinand caused World War I. The cause of World War I denotes this same function when it serves as a concealed question. And question intensions just are propositional concepts: they are functions from situations to propositions. Thus, if proposition descriptions denote propositional concepts, then we should 
expect them to serve as concealed questions when they complement question-taking verbs - which they do, if my suggestion in section 4 is correct.

So my solution to Prior's puzzle is quite unified. "Sally fears the proposition that Fido barks" and "Sally fears that Fido barks" have different truth conditions because the proposition that Fido barks denotes a propositional concept, not a proposition. If propositional concepts are also the meanings of concealed questions, then we would expect the proposition that Fido barks to conceal a question when it complements explains and other question-taking verbs - which is just what I suggested in section 4 . Thus, the data of section 4 provides independent confirmation of my solution to Prior's puzzle. Even if propositional concepts are not the meanings of concealed questions, there must be some other systematic connection between the noun phrases that give rise to Partee's puzzle and concealed questions. Since proposition descriptions give rise to Partee's puzzle, we can expect them to conceal questions and thus to denote things other than propositions - thereby solving Prior's puzzle in a way that allows that-clauses to denote propositions.

This solution to Prior's puzzle, however, would seem to generate a new Rundle-like puzzle. ${ }^{34}$ For if fears, hopes (for), and the like sometimes take propositional concepts as their objects, and if propositional concepts are the meanings of concealed questions, then we might expect these verbs to embed concealed questions. But they do not embed concealed questions, because they do not embed any questions.

A fully satisfactory response to this Rundle-like puzzle would require an answer to the following, more general question: why do some proposition-embedding predicates, but not others, embed questions? The simplest answer I know of is what Egré (2008) calls the factivity hypothesis (attributed to Hintikka 1975). According to the factivity hypothesis, a verb takes both declarative and interrogative complements only if it is factive, in the sense of presupposing its declarative complement. Here is an intuitive (and highly oversimplified) way of motivating this hypothesis.

Question-embedding verbs seem to come in two kinds. Some, such as wonders, express what Friedman (2013) calls question-directed attitudes: attitudes toward questions themselves, not toward any particular answers to these questions. Verbs that express question-directed attitudes cannot

34. I owe this objection to an anonymous reviewer. 
take that-clause complements:

(56) a. Sally wonders whether Fido barks.

b. *Sally wonders that Fido barks.

Other question-embedding verbs, such as knows, express what we might call answer-directed attitudes - in particular, attitudes directed toward true answers. When fed a propositional concept, knows (for example) returns a predicate that is true of an agent just in case she knows the actual value of that concept. What is distinctive about verbs that express answerdirected attitudes is that (plausibly, though controversially) for any verb $F$ that expresses such an attitude, and any question $q$ ? whose true answer is that $p$, one $F$ s $q$ ? only if one $F$ s that $p$. For example, if Fido barks, then (57a) below entails (57b).

(57) a. Sally knows whether Fido barks.

b. Sally knows that Fido barks.

If the only question-embedding verbs are those that express questiondirected attitudes and those that express answer-directed attitudes, so understood, then we can obtain the factivity hypothesis. For a nonfactive proposition-embedding verb cannot express a question-directed attitude (because it embeds propositions) or an answer-directed attitude (because such attitudes are essentially directed toward true answers).

On this simple picture, it is easy to explain why fears and hopes (for) do not embed concealed questions, despite taking propositional concepts as their objects. They do not embed concealed questions because they do not embed questions. They do not embed questions because they embed propositions (unlike wonders) yet are not factive (unlike knows). But they can take propositional concepts as their objects because they take arbitrary noun-phrase complements, some of which denote propositional concepts. It is possible, although very strange, to have an attitude toward a propositional concept that is neither question- nor answerdirected. Fear and hope are examples of such attitudes. Propositional concepts, when strangely ascribed as the objects of such attitudes, do not conceal questions.

Of course, this account raises at least two further questions: first, why verbs like fears and hopes (for) are not factive; and, second, whether and why the factivity hypothesis is correct. I do not know the answers to these questions. But they are questions for everyone. Their importance and difficulty are independent of my solution to Prior's puzzle. The point is merely that, given a general story about which proposition-embedding 
predicates can embed questions and why - a story that we need regardless of how we solve Prior's puzzle - we can explain why fears and hopes (for) do not embed concealed questions despite sometimes expressing attitudes to propositional concepts.

\subsection{Belief Reports Revisited}

The sentences below have the same truth conditions:

(58) a. Sally believes that Fido barks.

b. Sally believes the proposition that Fido barks.

How can this be explained on the hypothesis that the proposition that Fido barks denotes a propositional concept, not a proposition?

It would be ad hoc to claim that proposition descriptions are ambiguous, denoting propositions in belief reports and propositional concepts in reports of other attitudes. Fortunately, I do not think that such an ambiguity is required. Believes is peculiar in a way that can help explain why (58a) and (58b) mean the same thing.

The peculiar feature is that belief reports always seem to express relations between agents and propositions, even when the object of believes seems to denote a nonpropositional entity. Consider (59):

(59) a. I believe my mother.

b. I fear/love/hate my mother.

I doubt that (59b) expresses a relation between the speaker and a proposition. But a token utterance of (59a) is true just in case the speaker believes some contextually relevant proposition associated with her mother. Supposing, for example, that Sally's mother says that Fido barks, then a token utterance of (59a) by Sally may be true just in case (58a) is true. Nonetheless, my mother does not denote a proposition.

How can this help us explain why (58a) and (58b) mean the same thing? It depends on how our semantics of believes accommodates sentences like (59a). One possibility is that believes is polysemous. In one sense, it takes a proposition and returns a predicate that is true of an individual (e.g., Sally) just in case Sally believes that proposition. In another sense, it takes a nonpropositional entity (e.g., my mother) and returns a predicate that is true of Sally just in case Sally believes some contextually salient proposition associated with the entity-for example, that Fido barks (if Sally's mother says so). This polysemy would explain the strangeness (to my ear, at least) of sentences like, "I believe my mother and that Fido 
barks." I do not insist on this particular route. I claim only that we need some way to account for (59a) that does not assign my mother a proposition as its denotation: Sally's mother is a very nice person, not a proposition. (And even if my mother is ambiguous in this ad hoc way, it would seem no more or less ad hoc to claim that proposition descriptions denote propositions in belief reports but not elsewhere.)

Suppose we have such an account of believes as it occurs in sentences like (59a) - that is, some account of why, for some contextually salient proposition $p$ associated with the speaker's mother, a token utterance of (59a) is true just in case the speaker believes that $p$. And suppose the account does not require an occurrence of my mother to denote that $p$. Then we should not find it surprising for (58b) - "Sally believes the proposition that Fido barks" - to be true just in case Sally believes that Fido barks, even though the proposition that Fido barks does not denote that Fido barks. Consider, for example, the polysemy hypothesis I mentioned in the previous paragraph. We might think that, in (58b), believes takes a nonpropositional entity - the propositional concept denoted by the proposition that Fido barks - and returns a predicate that is true of Sally just in case she believes the contextually salient proposition associated with the entity: namely, that Fido barks. By contrast, in (58a) — "Sally believes that Fido barks"-believes simply takes a proposition-namely, that Fido barks - and returns a predicate that is true of Sally just in case she believes that Fido barks. This story could, if correct, explain why (58b) and (58a) have the same truth conditions even though the proposition that Fido barks and that Fido barks denote different things: the two senses of believes take different arguments but are systematically related in such a way that they return the same values in the cases at hand. Again, I do not insist that believes is polysemous. I claim only that we need some account of the peculiar behavior of believes in sentences like (59a), and that such an account seems likely to explain why (58b) and (58a) have the same truth conditions despite the proposition that Fido barks denoting a propositional concept.

The problem involving belief reports arose on my view because I said that proposition descriptions univocally denote propositional concepts. I was trying to avoid multiplying senses beyond necessity. But even if we are not sure whether proposition descriptions univocally denote propositional concepts, we can pass the buck of answering this question to the theory of individual concepts - or, more generally, to whatever our best solution to Partee's puzzle is. For recall that an analogous question arose in that context. If the number of insect species on Earth denotes an individual 
concept in, "The number of insect species on Earth is increasing," thenwe asked — wouldn't it have to be ambiguous between individual conceptdenoting and individual- (namely, number-) denoting senses? I said no. But if the answer is yes-if the number of insect species on Earth sometimes denotes a number, not an individual concept - then we need some principled account of when it denotes a number and when it does not. We might expect such an account to explain why, similarly, proposition descriptions sometimes seem to denote propositions - as in (58b) and sometimes not-as in (48b) and (49b). And those who think that proposition descriptions univocally denote propositions would likely also think the number of insect species on Earth univocally denotes a number, and thus need some other solution to Partee's puzzle. My hope is that, however we solve Partee's puzzle and its analogues for proposition descriptions - for example, (48) and (49) - we can use that solution to solve Prior's puzzle.

\subsection{Summary}

I have suggested that proposition descriptions do not denote propositions and thus need not be intersubstitutable salve veritate with thatclauses. This allows us to maintain that that-clauses denote propositions without appealing to a widespread ambiguity in predicates of propositional attitude.

Some might find my proposal to have a somewhat absurd flavor: how could the proposition that $p$ denote anything other than the proposition that $p$ ? It seems that the proposition that $p$ should denote the proposition that $p$ if anything does. My proposal, however, is no more absurd than the influential (although, of course, controversial) solution to Partee's puzzle, which I took for granted in section 5.1, according to which the number of insect species on Earth does not denote a number. Anyone sympathetic to that solution should be wary of dismissing my response to Prior's puzzle out of hand. Anyone unsympathetic to that solution needs some other response to Partee's puzzle, which can be extended to solve Prior's puzzle in a way analogous to the strategy I have suggested. ${ }^{35}$

35. For example, the view mentioned in note 30 would yield the following solution: although the proposition that $p$ officially denotes the proposition that $p$, the argument of fears in "Sally fears the proposition that Fido barks" is not the proposition that Fido barks but rather the intension of that proposition - that is, a propositional concept. By contrast, in "Sally fears that Fido barks," we can take that Fido barks to denote a truth value, whose intension (and thus the argument of fears) is a proposition. This view would allow us to 


\section{Conclusion}

My strategy in this article has been to draw connections between various puzzles about proposition descriptions and propositional attitude reports. We began with an analogue of Rundle's puzzle involving adjectives. A natural solution to that analogous puzzle allowed us to reduce Rundle's puzzle to Prior's puzzle. But this spelled trouble for King's solution to Prior's puzzle, because the ambiguity in propositional attitude verbs would spread implausibly to other expressions. So we sought another solution to Prior's puzzle-one that could also solve Künne's puzzle and explain why Prior's puzzle does not arise for believes. I suggested that Künne's puzzle, despite appearances, should not be solved along the lines of Rundle's puzzle, but rather by appealing to concealed questions, which cannot be embedded by believes. And we have independent reason to think that proposition descriptions serve as concealed questions, since they give rise to instances of Partee's puzzle - a solution to which can be naturally extended to solve Prior's puzzle in a more general way. If I am right, then we can solve Prior's puzzle without rejecting the standard view of propositional attitude reports or multiplying senses beyond necessity.

\section{References}

Abbott, Barbara. 2010. Reference. Oxford Surveys in Semantics and Pragmatics 2. New York: Oxford University Press.

Abbott, Barbara. 2011. "Support for Individual Concepts." Linguistic and Philosophical Investigations 10: 23-44.

Aloni, Maria. 2005. "Individual Concepts in Modal Predicate Logic." Journal of Philosophical Logic 34, no. 1: 1-64.

Aloni, Maria. 2008. "Concealed Questions Under Cover." Grazer Philosophische Studien 77, no. 1: 191-216.

Aloni, Maria, and Floris Roelofsen. 2012. "Interpreting Concealed Questions." Linguistics and Philosophy 34, no. 5: 443-78. doi.org/10.1007/s10988-011 $-9102-9$.

Arsenijević, Boban. 2009. "Clausal Complementation as Relativization." Lingua 119, no. 1: 39-50. doi.org/10.1016/j.lingua.2008.08.003.

Asher, Nicholas. 2011. Lexical Meaning in Context: A Web of Words. New York: Cambridge University Press.

maintain that propositional attitude reports express relations between agents and propositions, but not that that-clauses denote propositions, although they would have propositions as their semantic values in another sense. 
Bach, Kent. 1997. "Do Belief Reports Report Beliefs?” Pacific Philosophical Quarterly 78, no. 3: 215-41.

Bahna, Geraldine, and Norman B. Gordon. 1978. "Rehabilitation Experiences of Women Ex-Addicts in Methadone Treatment." International Journal of the Addictions 13, no. 4: 639-55. doi.org/10.3109/10826087809039291.

Baker, Carl Leroy. 1968. "Indirect Questions in English.” PhD diss., University of Illinois.

Balou18 [pseud.] 2010. “What a Rip-Off!'-TripAdvisor.” October 4. https:/ / www.tripadvisor.com/ShowUserReviews-g309284-d1420975-r82112 289-Hotel_Arenas_de_OSA-Puerto_Jimenez_Osa_Peninsula_Province_of _Puntarenas.html.

Barker, Chris. 2016. "Why Relational Nominals Make Good Concealed Questions.” Lingua. doi.org/10.1016/j.lingua.2016.01.002.

Betti, Arianna. 2015. Against Facts. Cambridge, MA: MIT Press.

Boër, Steven E. 2009. "Propositions and the Substitution Anomaly." Journal of Philosophical Logic 38, no. 5: 549-86. doi.org/10.1007/s10992-009-9106-x.

Božković, Željko. 1995. "Case Properties of Clauses and the Greed Principle*." Studia Linguistica 49, no. 1: 32-53. doi.org/10.1111/j.1467-9582.1995 .tb00464.x.

Bresnan, Joan, and Jane Grimshaw. 1978. "The Syntax of Free Relatives in English.” Linguistic Inquiry 9, no. 3: 331-91.

Cuba, Carlos de. 2017. "Noun Complement Clauses as Referential Modifiers." Glossa: A Journal of General Linguistics 2, no. 1. doi.org/10.5334/gjgl.53.

Deutscher, Guy. 2000. Syntactic Change in Akkadian: The Evolution of Sentential Complementation. Oxford: Oxford University Press.

Dixon, Robert M. W. 2005. A Semantic Approach to English Grammar. 2nd ed. Oxford Textbooks in Linguistics. New York: Oxford University Press.

Dolby, David. 2009. "The Reference Principle: A Defence.” Analysis 69, no. 2: 286-96. doi.org/10.1093/analys/anp017.

Egré, Paul. 2008. "Question-Embedding and Factivity." Grazer Philosophische Studien 77, no. 1: 85-125.

Elbourne, Paul. 2009. "Demonstratives as Individual Concepts." Linguistics and Philosophy 31, no. 4: 409-66. doi.org/10.1007/s10988-008-9043-0.

Ellis, Bret Easton. 2015. "Thoughts on David Foster Wallace and 'The End of the Tour.'”Medium, August 11. medium.com/@breteastonellis/thoughts -on-david-foster-wallace-and-the-end-of-the-tour-by-bret-easton-ellisfc9ba2d76d84.

Ellis, Jane. 1980. "USSR: The Christian Seminar." Religion in Communist Lands 8, no. 2: 92-112. doi.org/10.1080/09637498008430942.

FastMny [pseud.]. 2017. "Medical Marijuana, Inc. MJNA Post \# 205851.” Investors Hub, February 24. https://investorshub.advfn.com/boards/read_msg .aspx?message_id=128983945. 
Felappi, Giulia. 2015. “Sententialism: Why Not?” PhD thesis, King's College London.

Felder, Rachel. 2017. "Jennifer Meyer's Goal? 'Jewelry You Wear All the Time.'” New York Times, December 22. www.nytimes.com/2017/09/12/fashion /jewelry-jennifer-meyer-los-angeles.html.

Frana, Ilaria. 2006. "The de Re Analysis of Concealed Questions: A Unified Approach to Definite and Indefinite Concealed Questions." Semantics and Linguistic Theory 16: 17-34.

Frana, Ilaria. 2010. “Concealed Questions. In Search of Answers.” PhD diss., University of Massachusetts, Amherst. scholarworks.umass.edu/dissertations /AAI3409576.

Friedman, Jane. 2013. "Question-Directed Attitudes." Philosophical Perspectives 27, no. 1: 145-74. doi:10.1111/phpe.12026.

Geach, Peter Thomas. 1972. Logic Matters. Oxford: Basil Blackwell.

Geach, Peter Thomas. 1980. Reference and Generality: An Examination of Some Medieval and Modern Theories. 3rd ed. Ithaca, NY: Cornell University Press.

Gott, Merryn, Elisabeth Galena, Sharron Hinchliff, and Helen Elford. 2004. “'Opening a Can of Worms': GP and Practice Nurse Barriers to Talking about Sexual Health in Primary Care.” Family Practice 21, no. 5: 528-36. doi.org/10.1093/fampra/cmh509.

Grimshaw, Jane. 1992. Argument Structure. Rev. ed. Cambridge, MA: MIT Press.

Groenendijk, Joroen, and Martin Stokhof. 1982. "Semantic Analysis of WhComplements." Linguistics and Philosophy 5, no. 2: 175-233.

Haegeman, Liliane. 2012. Adverbial Clauses, Main Clause Phenomena, and Composition of the Left Periphery: The Cartography of Syntactic Structures. Oxford Studies in Comparative Syntax 8. New York: Oxford University Press.

Harman, Gilbert. 2003. "Category Mistakes in M\&E." Philosophical Perspectives 17, no. 1: 165-80. doi.org/10.1111/j.1520-8583.2003.00007.x.

Harrison, Glenn W., Morten I. Lau, and Hong Il Yoo. 2014. "Risk Attitudes, Sample Selection, and Attrition in a Longitudinal Field Experiment." CEAR Working Paper 2014-04. Atlanta: Georgia State University. cear.gsu .edu/wp-2014-4.

Healthtalk Australia. 2016. "Future Goals and Aspirations." December 22. research.healthtalkaustralia.org/experience-ageing/future-goals-and -aspirations.

Heim, Irene. 1979. “Concealed Questions.” In Semantics from Different Points of View, ed. Rainer Bäuerle, Urs Egli, and Arnim von Stechow, 51-60. Springer Series in Language and Communication 6. Berlin: Springer. doi.org /10.1007/978-3-642-67458-7_5.

Heim, Irene, and Angelika Kratzer. 1998. Semantics in Generative Grammar. Blackwell Textbooks in Linguistics 13. Malden, MA: Blackwell. 
Higgins, Francis Roger. 1973. "The Pseudo-Cleft Construction in English.” PhD diss., Massachusetts Institute of Technology. dspace.mit.edu/handle /1721.1/12988.

Hintikka, Jaakko. 1975. "Different Constructions in Terms of the Basic Epistemological Verbs: A Survey of Some Problems and Proposals." In The Intensions of Intentionality and Other New Models for Modalities, 1-25. Dordrecht: D. Reidel.

Jackendoff, Ray S. 1971. "Gapping and Related Rules.” Linguistic Inquiry 2, no. 1: 21-35.

Janssen, Theo. 1984. "Individual Concepts Are Useful." In Varieties of Formal Semantics: Proceedings of the Fourth Amsterdam Colloquium, September 1982, ed. Fred Landman and Frank Veltman, 171-92. Dordecht: Foris.

Kayne, Richard S. 2009. "Antisymmetry and the Lexicon.” Linguistic Variation Yearbook 8: 1-32. doi.org/10.1075/livy.8.01kay.

King, Jeffrey C. 2002. "Designating Propositions.” Philosophical Review 111, no. 3 : 341. doi.org/10.2307/3182547.

King, Jeffrey C. 2007. The Nature and Structure of Content. New York: Oxford University Press.

Klemens, J. J., E. Mhoon, and M. Redleaf. 2007. "Is Simultaneous Bilateral Mastoidectomy Ever Advisable?” Journal of Laryngology and Otology 121, no. 11: $1041-47$.

Kripke, S. 1992. "Individual Concepts: Their Logic, Philosophy, and Some of Their Uses." Proceedings and Addresses of the APA 66: 70-73.

Künne, Wolfgang. 2003. Conceptions of Truth. New York: Oxford University Press.

Künne, Wolfgang. 2014. “Truth without Truths?” In The History and Philosophy of Polish Logic: Essays in Honour of Jan Woleński, ed. Kevin Mulligan, 160-204. New York: Palgrave Macmillan.

Löbner, Sebastian. 1981. "Intensional Verbs and Functional Concepts: More on the 'Rising Temperature' Problem.” Linguistic Inquiry 12, no. 3: 471-77.

Löbner, Sebastian. 1985. "Definites." Journal of Semantics 4, no. 4: 279-326. doi.org/10.1093/jos/4.4.279.

Löbner, Sebastian. 2015. "Functional Concepts and Frames." In Meaning, Frames, and Conceptual Representation, ed. Thomas Gamerschlag, Doris Gerland, Rainer Osswald, and Wiebke Petersen, 15-42. Düsseldorf: Düsseldorf University Press.

Loukanova, Roussanka, and M. Dolores Jiménez-López. 2012. "On the SyntaxSemantics Interface of Argument Marking Prepositional Phrases.” In Highlights on Practical Applications of Agents and Multi-Agent Systems, 53-60. Berlin: Springer.

Merlo, Paola, and Eva Esteve Ferrer. 2006. "The Notion of Argument in Prepositional Phrase Attachment.” Computational Linguistics 32, no. 3: 341-78. doi.org/10.1162/coli.2006.32.3.341. 
Mishtal, Joanna Z. 2009. “Matters of 'Conscience': The Politics of Reproductive Healthcare in Poland.” Medical Anthropology Quarterly 23, no. 2: 161-83. doi.org/10.1111/j.1548-1387.2009.01053.x.

Moffett, Marc A. 2003. "Knowing Facts and Believing Propositions: A Solution to the Problem of Doxastic Shift.” Philosophical Studies 115, no. 1: 81-97.

Moltmann, Friederike. 2003. "Propositional Attitudes without Propositions." Synthese 135, no. 1: 77-118.

Moltmann, Friederike. 2013. Abstract Objects and the Semantics of Natural Language. 1st ed. Oxford: Oxford University Press.

Montague, Richard. 1973. "The Proper Treatment of Quantification in Ordinary English.” In Philosophy, Language, and Artificial Intelligence, ed. Jack Kulas, James H. Fetzer, and Terry L. Rankin, 141-62. Studies in Cognitive Systems 2. Dordrecht: Springer Netherlands. doi.org/10.1007/978-94-009 $-2727-8$-7.

Nathan, Lance Edward. 2006. “On the Interpretation of Concealed Questions.” PhD diss., Massachusetts Institute of Technology.

Oliver, Alex. 2005. "The Reference Principle." Analysis 65, no. 3: 177-87. doi.org/10.1093/analys/65.3.177.

Parsons, Terence. 1993. "On Denoting Propositions and Facts." Philosophical Perspectives 7: 441. doi.org/10.2307/2214134.

Partee, Barbara H. 1974. "Opacity and Scope." In Semantics and Philosophy, ed. Milton K. Munitz and Peter K. Unger, 81-101. New York: New York University Press.

Partee, Barbara H., and V. Borschev. 2012. "Sortal, Relational, and Functional Interpretations of Nouns and Russian Container Constructions." Journal of Semantics 29, no. 4: 445-86. doi.org/10.1093/jos/ffs009.

Percus, Orin. 2014. "What Concealed Questions Might Conceal.” In The Art and Craft of Semantics: A Festschrift for Irene Heim, Vol. 2, ed. Luka Crnič and Uli Sauerland, 23-45. MIT Working Papers in Linguistics 71. Cambridge, MA: Massachusetts Institute of Technology.

Prior, A. N. 1963. "Symposium: Oratio Obliqua." Proceedings of the Aristotelian Society, Supplementary Volumes, 37: 115-46.

Prior, A. N. 1971. Objects of Thought, ed. P. T. Geach and A. J. P. Kenny. Oxford: Oxford University Press.

Pryor, James. 2007. "Reasons and That-Clauses." Philosophical Issues 17, no. 1: 217-44. doi.org/10.1111/j.1533-6077.2007.00131.x.

Romero, Maribel. 2005. "Concealed Questions and Specificational Subjects*." Linguistics and Philosophy 28, no. 6: 687-737. doi.org/10.1007/s10988-005 -2654-9.

Romero, Maribel. 2006. "On Concealed Questions." Proceedings of Semantics and Linguistic Theory 16: 208-27. doi.org/10.3765/salt.v16i0.2945.

Rosefeldt, Tobias. 2006. “That'-Clauses and Non-Nominal Quantification.” Philosophical Studies 137, no. 3: 301-33. doi.org/10.1007/s11098-006-0002-8. 
Rundle, B. 1967. "Transitivity and Indirect Speech.” Proceedings of the Aristotelian Society 68: 187-206.

Schiffer, Stephen R. 2003. The Things We Mean. New York: Oxford University Press.

Takami, Ken-ichi. 1992. Preposition Stranding: From Syntactic to Functional Analyses. Berlin: De Gruyter.

Trueman, Robert. 2012. "Dolby Substitution (Where Available)." Analysis 72, no. 1: 98-102. doi.org/10.1093/analys/anr137.

Trueman, Robert. 2018. "Substitution in a Sense." Philosophical Studies 175, no. 12: 3069-98. doi.org/10.1007/s11098-017-0995-1.

Uegaki, Wataru. 2016. "Content Nouns and the Semantics of Question-Embedding.” Journal of Semantics 33, no. 4: 623-60. doi.org/10.1093/jos/ffv009.

Wright, Crispin. 1998. "Why Frege Did Not Deserve His 'Granum Salis.' A Note on the Paradox of 'The Concept Horse' and the Ascription of 'Bedeutungen' to Predicates." Grazer Philosophische Studien 55: 239-63. 